\title{
O FINANCIAMENTO DA GRANDE EMPRESA DE CRISTÓVÃO COLOMBO.
}

A maioria quase que absoluta dos historiadores que se têm ocupado de Colombo, deixa-se empolgar pelas controvérsias sôbre a sua origem; acêrca da veracidade ou não das cartas que Toscanelli lhe enviou; sôbre a veracidade ou não da viagem de um piloto desconhecido que, tendo descoberto o Novo Mundo antes do Genovês, lhe ensinou a rota; a respeito das cartas que Colombo enviou a Luís de Santangel e Gabriel Sanchez dando notícia da sua feliz viagem e por outras questões que reputamos de somenos importância. Porém, nenhum dêles estudou a fundo, como fêz Rinaldo Gaddeo, o assunto que diz respeito ao financiamento da grande emprêsa do Almirante do Mar Oceano.

Dêsse modo tudo justifica fazermos a tradução para o verráculo e publicarmos nesta Revista o estudo do referido historiógrafo italiano que, sob o título Il finanziamento dei primo viaggio e l'opera dei capitalisti italiani di Spagna, foi publicado ccmo apêndice na Historie della vita è dei fatto di Cristoforo Colombo, da autoria de seu filho D. Fernando, novamente edit?da em Milão pela Edizioni Alpes.

"Uma circunstância muito singular que nunca adeqüadamente chamou a atenção dos historiadores - talvez porque só nos últimos anos vieram à luz novos documentos a ela referentes - é a continuidade das relaçóes de interêsse e de amizade entre Colombo e alzuns membros das grandes casas bancárias, comerciais e de armadores genoveses que tinham sede em Gênova e filiais em Portugal - Espanha".

"Colombo realizou a sua primeira viagem de importância, em 1474 ou 1475 em navio armado pelos Spinola e pelos Di Negro, êstes últimos associados dos Centurione; em 1476 participou de uma frota dos Di Negro, dos Spinola, dos Italiano e dos Doria; em Portugal recebeu auxilio de Paolo Di Negro, de Luigi Centurione Scoto e de Antônio Basso, e comerciou por conta do mesmo Di Negro e do mesmo Centurione; na Espanha, depois do descobrimento, os seus banqueiros, os seus procuradores de negócios são ainda os Di Negro, os Centurione, os Spinola, os Doria e depois os Pinello, os Grimaldi, os Cattaneo, os Rivarolo, os Berardi e assim por diante. (Depois da 
morte do Almirante [1506] os filhos, os irmãos dêle, continuaram mantendo relações de negócios com aquêles mesmos banqueiros e com aquêles mesmos comerciantes). Por mais de trinta anos, pois, Colombo foi sócio e amigo das mais importantes casas comerciais: genovesas que ampliavam os seus negócios nos principais centros da Península Ibérica. Tudo isto tem uma grande significação para se poder compreender certas circunstâncias da vida do Almirante".

"Em Portugal, Colombo comerciou e navegou: de algumas de. suas realizaçōes comerciais na Madeira e na Africa, temos precisas. referências; mas desde que se transferiu para a Espanha, nenhuma ocupação fixa e regular lhe podemos atribuir, mediante a qual pudesse prover as suas necessidades, aquelas dos filhos e da amante. Que tenha desenhado mapas e vendido livros, é admissivel, mas isso ocorreu por pouco tempo. Tem-se notícia de que recebeu auxilio. da Côrte, mas êles foram escassos e irregulares. $O$ duque de Medina Celi deu-lhe hospedagem na sua própria casa, por dois anos; esto hospedagem não foi continua mas sim intermitente, não se podendo precisar se realmente durou o que o duque afirmou. Em conclusão, não estamos habilitados a saber com segurança, como viveu Colombo na Espanha durante sete anos".

"Já vimos nas notas do texto, no seu lugar adeqüado, como deve. ser considerado o fato do Genovês não ir a Castela por acaso, mas. com recomendações dos seus concidadãos de Lisboa aos seus conciāadáos de Sevilha e de outros centros espanhóis. Os Spinola, os Di Negro, os Centurione estabelecidos em Portugal tinham na Espanha: membros da própria família associados nos tráficos e nos negócios bancários. Para falar só dos Centurione, nós temos a certeza dos: seguintes: Cristóforo Centurione, comerciante em Valência, Martino Centurione, chefe de uma casa bancária em Granada, Gaspare Centurione, banqueiro em Sevilha, Melchiore Centurione, comerciante. em Cádiz, etc. os quais tiveram negócios em comum com Colombo: desde o tempo do descobrimento.- Estas relações é difícil supor que tenham começado só depois da volta da grande viagem em 1493, antes é de se recordar que tinham sido iniciadas logo após a chegada: do Genovês em Castela: a amizade que Colombo demonstra por êstes seus financiadores e a solicitude pelos seus interêsses são assim. evidentes para fazer supor não só relações anteriores mas ainda. prova de gratidão".

"De que espécie foram as apresentações e as recomendações de. que os genoveses de Portugal muniram Colombo junto aos genoveses da Espanha, é fácil perceber. Elle não chegava a Cádiz e a Sevilha para pedir uma ocupação ou trabalho: êle chegava com o propósito determinado e manifesto de oferecer a $D$. Fernando e a $D$. Isabel um plano de navegação e de descoberta no Extremo Ocidente; êste plano, pelo qual tanto se afadigou em Lisboa, era por conseguinte bem. conhecido dos genoveses daquela cidade, e as recomendações referidas deviam visar principalmente a induzir os concidadãos residentes na Espanha a prestar todo o seu apôio a Colombo, de modo que êle pudesse apresentar-se às personagens mais influentes da Côrte e pudesse por meio delas ser recomendado aos soberanos. O próprio 
fato de ter sido êle admitido na Côrte em tempo relativamente curto e de ter tido como primeiros protetores Luís de Santangel e Alonso de Quintanilla, ambos chefes do ministério das finanças do Estado. portanto em imediato contacto com o elemento bancário e comercial italiano que tinha nas mãos, em grande parte, a vida econômica da nação, atesta como Colombo foi recebido e ajudado pelos seus próprios concidadãos".

Esta colaboração ativa dos italianos da Espanha a favor de Colombo, e que veremos tornar-se decisiva no momento critico da sua ação, não se pode explicar como um simples ato de solidariedade nacional: ela indica uma adesão plena à sua idéia e aos seus planos. Aquêles financeiros, aquêles mercadores não eram certamente cosmógrafos e idealistas; talvez sorrissem das consideraçōes de indole religiosa com as quais Colombo, em parte sinceramente, em parte constrangidamente, procurava abrir brecha no ânimo do séquito da rainha Isabel; mas com o bom senso de homens práticos e dispostos a considerar os mais vastos e audazes intentos, não deviam achar nem quimera, nem irrealizável o projeto de seu compatriota. A procura de uma nova rota para a fndia era para os italianos do fim do quatrocento um problema vital, ao qual já dois séculos antes os genoveses irmãos Vivaldi tinham tentado dar uma solução: encontrar êsse caminho mais fácil e mais curto e, portanto, mais econômico daquele do Mar Vermelho e do Gôlfo Pérsico e das longas e trabalhosas caravanas da Pérsia para o transporte e venda na Europa das especiarias, do ouro e das pedras preciosas do Extremo Oriente, era para êles naquele tempo em que os portuguêses penetravam sempre mais profundamente em direção ao sudeste seguindo a costa africana, uma necessidade inexorável. O costume dos mercadores italianos não consistia só em freqüentar e desfrutar os mercados já conhecidos, mas também, tradicionalmente, em descobrir e abrir novos mercados. Estivessem ou não convencidos das argumentações cosmográficas ou pseudo-cientificas de Colombo, as razões práticas que êle expunha, encontrava neles plena acolhida. De la Rocière, seguido De Hevesy e de Pessagno, revelaram a tendência que animava a casa mundial dos Centurione, que além da Espanha e Portugal, tinha os seus escritórios em França, Flandres, Países-Baixos, nos portos principais do Mediterrâneo, todos dependentes da matriz de Gênova, e que promovia verdadeiras indagações à procura de metais preciosos e de produtos coloniais do interior da África, do Oriente, da Rússia, e depois do descobrimento do Novo Mundo se arrojam a levar para lá o seu comércio. Colombo era do circulo de interêsses e de idéias desta casa, era um de seus agentes; a analogia das diretivas, a prova de trinta anos de ininterruptas. relações de negócios começadas em 1474 e interrompidas só com a morte do Almirante, evidencia os esforços de Colombo em realizar uma viagem que tinha por escopo a procura de uma nova rota para a india e que foram aprovados e auxiliados pelos mercadores italianos residentes na $\mathrm{Pe}$ ninsula Ibérica".

"A conclusão de que êstes mercadores tinham provido, em parte, as necessidades do Genovês durante os sete anos de trabalhosa 
vida espanhola, se nos apresenta, pois, natural. Falaram de um estedo de indigência em que Colombo teria se encontrado durante aquêle periodo; isso é compreendido com discreção: Colombo parece pobre em verdade, só durante o tempo que precedeu imediatamente o acolhimento definitivo de seu projeto, quando os soberanos the disseram de modo claro que não podiam fazer nada por êle. A repulsa da Côrte, tirando tôda a esperança a Colombo e aos que o apoiavam, deve ter induzido êstes a afrouxar ou francamente a suprimir os subsídios que até então tinham concedido ao seu concidadão; mas quando uma imprevista circunstância política fêz divisar uma nova possibilidade do sucesso, êles se reuniram de novo em tôrno de Colombo e tentaram o último golpe que levou ao sucesso definitivo as aspirações de todos".

"O golpe de Santa Fé se apresenta verdadeiramente estonteante $\epsilon$ inexplicável. A primeira licença da Côrte foi no fim de 1490 ou 1491. Voltando a Palos para encontrar o filho Diego e partir para : França, o padre Juan Pérez quis fazer uma outra tentativa junto ‘ rainha' Isabel, mas sem resultado. A nova licença de Colombo é do fim de 1491 e a partida nos primeiros dias de janeiro de 1492 . Ele toma amargamente o caminho da França; quando perto da Porta $\mathrm{Pi}$ nos; fora de Granada, é procurado por um mensageiro da rainha Isabel e reconduzido ao Campo de Santa Fé, onde o seu projeto é aprovado e as extraordinárias exigências de títulos, de honorários e recompensas por êle impostas são integralmente aceitas. Os historiadores são unânimes em atestar que esta clamorosa mudança se deve $\dot{a}$ intervenção de Luís de Santangel, o quàl, oferecendo-se para assumir a responsabilidade das despesas inerentes a expedição, tinha levado a rainha Isabel a dar o consentimento à emprêsa. Eis portanto que Santangel, que tinha pouca influência junto a D. Isabel, em comparação com os grandes personagens que, segundo a tradição deviam patrocinar a causa do Genovês, seja referido, funcionário da Côrte de Aragão e não de Castela, vence de um momento os obstáculos que por tantos anos tinham paralisado tôdas as tentativas de Colombo. As objeções de ordem cosmográficas, que na repulsa do grande plano tinha representado uma parte preponderante, diremos melhor única, desapareceu como a neblina ao vento. A Colombo concedem os meios de realizar uma emprêsa que foi sempre considerada, até poucos dias antes, como irrealizável! Quiseram explicar que êste estranhíssimo acontecimento com o zêlo religioso da rainha Isabel, diante da conquista de Granada que libertava os soberanos de uma grande preocupação; mas o zêlo místico de $D$. Isabel não nasceu com a queda do último reino muçulmano, nem o consentimento para a expedição exigia um tão grande desvio de pensamento e de meios que não pudessem encontrar o seu lugar entre as menores atividades dos dois reinos espanhóis. Portanto, outros motivos, outras poderosas razões devem ter influido nos acontecimentos que culminaram com a volta de Colombo e com a capitulação de 17 de abril em Santa Fé em favor do seu plano". 
"Fica evidenciado que, na fase final da tentativa os prelados, os homens políticos, os letrados e os competentes, não tiveram nenhuma interferência".

"Consideremos a figura de Santangel, que aparece como o Deus ex-machina do prodigioso acontecimento. Era êle de antiga familia hebraica de Valência, convertido não pelo amor mas pela fôrça ao cristianismo. Seu pai chamava-se Luís è era arrendatário e concessionário da arrecadação da alfândega de sua cidade e nessa qualidade teve o encargo do monarca de Aragão de dirimir uma controvérsia com representantes do Duque de Milão e da cidade de Gênova relativamente a importação de peixes salgados e panos de lã da Lombardia (1), comércio que estava nas mãos dos mercadores genoveses. Em seguida Santangel pai teve arrendamiento dos direitos de pedágio e de alfândega que pagavam os genoveses de Valência. Por sua morte, lhe sucedeu nos mesmos direitos o filho e herdeiro universal Luís de Santangel, o personagem de que nos ocupamos, ao qual o rei D. Fernando pela cédula de 17 de fevereiro de 1479 , confirmou tais direitos (jus pedatici et Jannuensium). Aqui temos uma primeira indicação relativa às pessoas e a negócios de Santangel com elemento comercial genovês na Espanha. Estabelecido em Barcelona à frente de uma agência comercial, foi nomeado depois receptor de las pecunias do antigo patrimônio real de Valência e mais tarde, em 1481, escribano de ración. Como nota Serrano y Sanz (2), o ofício de escribano de ración era mais modesto do que alguns tinham imaginado, e consistia em realidade na guarda dos livros de contas da casa do rei de Aragão. Estes empregos públicos não impediam, porém, de Santangel imiscuir-se em negócios de qualquer espécie, visto que, como cbserva Serrano y Sanz, como legítimo descendente de judeus, não sabia viver a não ser junto à mesa de cambistas ou banqueiros e à sombra do banco dos cobradores de impostos e dos agentes de câmbio. De 1478 a 1484, junto com o irmão Jaime, obtivera a concessão dos direitos italianos e genoveses".

"Ora, é o próprio Santangel que, segundo D. Fernando Colombo (3) e os historiadores antigos, teria proposto à rainha Isabel prestar-lhe um pequeno serviço, emprestando-lhe dinheiro, o que a rainha aceitou e por isso chamou de novo Colombo e lhe concedeu o necessário para organizar a expedição. O fato está comprovado por documentos originais que veremos. Perguntemos, entretanto, por que razão Santangel, desde o primeiro comparecimento de Colombo na Côrte, em 1486 em Córdova, e depois de modo tão decisivo em janeiro de 1492 em Santa Fé, manifestou-se tão favorável à causa do Genovês quando todos os poderosos não o apoiavam ou apenas o amparavam só com palavras? Falaram em solidariedade de raça; fábula: nas veias de Colombo não corria uma só gôta de sangue hebraico; afinidade psicológica: fábula; se existiu um homem diferente de Colombo foi verdadeiramente Santangel, banqueiro e negociante

(1). - Serrano y Sanz, D. Manuel, origens de la dominación española en America, 1, p. C e seg.

(2). - Ibidem, 1, p. CVIII.

(3). - D. Fernando Colombo, La Historia della vita e dei fati di Cristofaro Colombo, Venezia, 1571, capítulo XIV. 
sem entusiasmo, sem fantasia e sem espirito humanista; solicitude religiosa: fábula; dez membros de sua família foram torturados entre 1486 e 1496 por heresia (4), e é fácil imaginar que zêlo êle podia dispensar na propagação de uma fé que lhe dizimava os parenles e ameaçava êle próprio; avidez de lucros: fábula; porque a operação do financiamento da viagem colombiana lhe dava a irrisória recompensa de poucos milhares de maravedis, que devia dividir com o sócio. Enfim, por mais que se procure, não se encontra razão que possa explicar Santangel a desafiar a maledicência da maioria dos: poderosos da Côrte que eram contrários a Colombo, a empregar o seu dinheiro numa emprêsa que devia naturalmente supor fantástica, a arriscar dar um passo em falso e comprometer a sua posição pessoal no caso do insucesso da emprêsa, que se baseava só no apôio do rei Fernando".

"O Almirante disse em um Memorial de Agravios publicado pela Duquesa d'Alba (5) que êle em pessoa fêz metade das despêsas da primeira viagem porque os soberanos não quiseram dar mais que um conto: fizo la myetad del gasto y puso su persona porque Sus Altezas para este negocio no le quisieron dar mas de un cuento, y a él fué necessario de prover de medio porque no abastaba para tai hecho. A mesma declaração fêz no seu testamento de 1506: SS. AA. no gastaron ni quisieron gastar para ello, salbo un quento de maravedis, é á mi fué necessario de gastar el rresto (6). A despêsa da viagem que terminou com o descobrimento da América foi, pois, de. dois contos ou seja dois milhões de maravedis, ou cêrca de 30.000 liras de antes da guerra".

"D. Fernando Colombo e outros historiadores antigos dizem que a soma referente a viagem foi inteiramente fornecida por Santangel; outros dizem que proveio do tesouro de Aragão; outros acreditam na lenda de ter a rainha Isabel empenhado as suas jóias. Mas a verdade é bem diversa: a metade da soma foi fornecida por Colombo, e a outra aparentemente por Luís de Santangel. Os documentos confirmam as palavras de Colombo na parte que lhe diz respeito. e prova a interferência direta de Santangel de outro lado.".

“Êsses são:

1. ${ }^{\circ}$ - Arquivo de Simancas, Contadoria mayor, primeira epoca, serie 131, "Relacion de los alcances que se hazen de las quentas de 1: Hermandad a Luys de Santangel e Francisco Pinelo, de cada quen-: ta por si, e del descargo e del alcance liquido que queda". Dêste livro: de contas da Sancta Hermandad resulta que Luis de Santangel e Fran-: cisco Pinelo eram tesoureiros e exatores daquela associação, e que a: êles foi creditada a quantia de 1.140 .000 maravedis emprestados "a. Suas Altezas para el despacho de Cristobal Colón Almirante", pela cédula do rei datada de 2 de maio de 1492. A Santangel foram ain-:

(4). - Kayserling, M., Christoph Columbus, etc., pp. 61-71.

(5). - Duquesa d'Alba, Autógrafos de Colón, Madrí, 1892, p. 28.

(6). - De ollis, Cesare, Scritti di Cristofaro Colombo, "Raccolta Colombiana", II, 263. 
da creditados 17.100 maravedis "que monta su salario que les per-: tence de los 15 maravedis al millar de la paga".

2..$^{\circ}$ - Arquivo de Simancas. Ut supra. Repete a menção dos 1.140.000 maravedis "que paresce que prestò el Escrivano de racion para el despacho del Almirante de las Yndias".

3. ${ }^{\circ}$ - Arquivo de Simancas. Ut supra. De uma cédula de 30 de setembro de 1495 de Fernando e Isabel resulta que Santangel "nuestro Escribano de racion, e del nuestro Consejo" e Francisco Pinelo "nuestro jurado e fiel executor de la muy noble cibdad de Sevilla", exerceram o cargo de "Thesoreiros generales" da Hermandad de agôsto de 1490 a agôsto de 1493 e emprestaram ao rei para a guerra "de los moros" 12.000 ducados. A cédula acrescenta: "Vos fueran recebidos e pasados en quenta un quento e ciento e quarenta mil maravedis que diestes por nuestro mandado al obispo d'Avida que agora es Arçobispo de Granada, para el despacho del Almirante Cristobal Colón, e otros diez e siete mill e cient maravedis por vuestro salario de la paga dellos, que son un cuento e ciento cinquenta e syete mill e cient maravedis".

"Provada a verdade do empréstimo feito ao rej por Santangel e Pinelo, resta ver quem fôra êste Francisco Pinelo, que aparece como colega e sócio do "escribano de ración". Ele não era outro senão Francisco Pinello, genovès, da antiga família dos Pinelli que em 1528 deu o próprio nome a um dos vinte "Alberghi" da Soberba. Dêle sabemos que habitava em Valência, a cidade de Santangel, quando êste aí residia; que se transferiu para Sevilha como jurado régio e verificador dos pesos - fiel executor da cidade de Sevilha -; que foi colega de Santangel na direção da tesouraria geral da Saneta Hermandad. Temos também notícia que Pinello foi fiador dos soberanos em um empréstimo de 5 milhões de maravedis que êstes contrairam junto ao duque de Medina Sidônia e que do seu, emprestou ao rei um milhão de maravedis, para o transporte para a Africa elo último rei de Granada".

"Do que tenho exposto sôbre os dois personagens resulta, para Santangel: que tanto seu pai como êle mantiveram antigas e estreitas relações com elementos comerciais genoveses. Quanto a Pinello: que êle foi amigo, associado, colega de Santangel em negócios públicos e privados e em cargo oficial. Há mais: em uma ordem de pagamento expedida pelo rei Fernando a Santangel em 1483 (7), diz que tendo tido o rei necessidade de "cierta cantidad de dinero, non se encontrò mejor medio que el de que lo tomara Luís (de Santangel) de dos mercadores genoveses, Cristobal Centurione y Benito Pinello".

Desde 1483, portanto, Santangel pedia dinheiro emprestado a um Pinello e a um Centurione para dá-lo por sua vez como empréstimo ao rei de Aragão".

"Francisco Pinello não foi apenas amigo e sócio de Santangel, foi amigo íntimo e fraterno de Cristóvão Colombo. Bastaria para is-

(7). - Sanpere y Miguel, Barcelona en 1492, p. 69. 
so atestar o fato dêle tornar-se fiador da restituição aos canônicos do capitulo da catedral de Sevilha, da padiola que emprestaram ao enfêrmo e decadente Almirante para a sua viagem à Côrte. Não é só: Pinello tomou parte preponderante nos preparativos da segunda viagem de Colombo e teve o encargo especial de fornecer ao Almilante e a Fonseca os fundos necessários; em 1503, quando foi instituída a Casa de Contratación, ou seja o serviço administrativo da Índia, foi nomeado factor dela, e foi mantido em tal cargo em 1505 c em 1507; foi êle que em 1505 se uniu ao doutor Matienzo, por ordem real, com Colombo, para resolver algumas dúvidas a respeito dos marinheiros que participaram da quarta viagem. Um Bernardo Fynelo, com tôda probabilidade seu parente e talvez seu filho, emprestou dinheiro a dois parentes de Colombo em 1497 (8). E' a um filho de Francisco Pinello que Colombo confia duas cartas para o próprio primogênito Diogo, na primeira da qual, de $1^{\circ}$ de dezembro de 1504, recomenda que dê boa acolhida ao portador, para que faça por êle tudo quanto puder. "Esta carta leberá un hijo de Francisco Pinelo. Házale buen allegamento, porque haz por mi todo lo que puede".

"Que se pode deduzir lògicamente desta série de dados? Que Colombo e os seus amigos genoveses, tendo à frente Pinello, quando viram que as longas tentativas eram interrompidas e que não era mais possível reiniciá-las então com a surrada discussão cosmográfica e teológica, resolveram mudar de método, apresentando o projeto sob o exclusivo aspecto de uma operação comercial do qual êles estavam prontos a participar diretamente, e para o qual procuraram um patrocinador junto ao rei Fernando: o seu ministro Santangel. Não sabemos se êste participou da ação resolutiva por amor ou por fôrça: devido à particular função de provedor confidencial dos capitais que, em consideração a seu rei êle tinha assumido, certo é que êle estava nas mãos do elemento bancário e comercial italiano. E' preciso levar em conta uma circunstância importantíssima que ocorreu em princípio de 1492: a batida geral aos hebreus da Espanha. O famoso e iniqüo decreto tem a data de 30 de março, mas antes dêle ser baixado, como atesta Zurita (9), "se avia ya proveydo que los judios saliessen de todos los lugares del Andaluzia". Com a batida aos hebreus o poder e prestígio dos homens italianos de negócios aumentaram consideràvelmente, uma vez que nenhuma outra fôrça econômica existia na Espanha que pudesse fornecer ao rei, por intermédio de Santangel ou de Gabriel Sánchez, tesoureiro geral de Aragão e amigo certo de Colombo, os meios financeiros liqüidos dos cuais êle tinha necessidade. A analogia que se pode estabelecer entre a expulsão dos judeus e o golpe teatral de Santa Fé, encontra-se em evidência no prólogo de Colombo no seu Jornal de Bordo: "Así que, después de aver echado fuera todos los judios de todos vuestros reynos y señorios, en el mesmo mes de enero mandou $V$. A. a mi

(8). - De Lollis, Cesare, obra citada, vol. II, p. CXI.

(9). - Historia del Rey D. Mernando el Catholico, fol. 8 da ediçăo de Zurita de 1580 . 
com armada..." O decreto público da batida geral dos hebreus é, como se disse, de 30 de março, porém, além do fato assinalado por Zurita, de uma expulsão parcial de hebreus da Andalusia que a precedeu, é de supor que uma decisão de tanta importância não fôsse. tomada de improviso, mas fôsse ao invés largamente debatida nos conselhos da Corôa, e que desde princípios de janeiro fôsse não só ventilada mas resolvida. Não é fantasia pensar que o elemento capitalista italiano da Espanha tenha contribuído com tôda a sua fôrça para a determinação de tal medida que privava de meios a concorrència dos financeiros hebreus, e que tal elemento tenha assumido junto ao rei Fernando o compromisso de prover tôdas as necessidades de capitais da Côrte e do Estado. Ficando absolutamente donos do campo, êsses devem ter solicitado do rei um favor que nada lhe custava: aquêle de deixar dar curso a emprêsa do seu compatriota, a qual seria levada a efeito com o exclusivo risco e perigo dêles, sob a condição de que, em caso de insucesso, os soberanos e o Estado ficariam exonerados de qualquer responsabilidade e, no caso de êxito, seriam largamente recompensados política, econômica e territorialmente".

"Em todos êsses acontecimentos, o acôrdo entre Colombo, Pinello, Santangel e o rei Fernando fica evidenciado. Monsenhor Geraldini (10) levanta um pouco o véu do mistério mostrando Colombo e Santangel em colóquios para determinar a importância da despêsa, que o Genovês estimava em 3.000 moedas de ouro: tribus millibus aureorum... necesse est. Colombo pôs à disposição a metade da soma que foi calculada: um milhão de maravedis; mas sôbre a procedência de tal quantia nenhuma dúvida pode existir, dado o notório estado de pobreza em que vivia naquele tempo Colmbo: são os banqueiros e mercadores italianos que lhe emprestaram com plena confiança. De quatro dêles temos clara e segura referência. Em uma nota manuscrita em um volume da coleção do frade Antônio de Aspa lê-se que, segundo o que disseram alguns que nararram a primeira viagem de descobrimento, Colombo "fue ayudado de tres Ginoveses mercadores, que al uno clamavam Jacobo de Negro, que tenia en aquel tempo mucho credito en Sevilla, y al altro llavaman Capatel $y$ estava en Xeres, $y$ al otro llamavan Luis Dorio que morava en Cadiz" (11). Em um ato notarial de 15 de dezembro de 1495, o mercador e armador florentino Zuanoto Berardi, agente em Sevilha da grande Casa dos Medici, da qual participava Amerigo Vespucci como procurador, declarava que Colombo, como constava da sua conta-corrente, lhe devia cêrca de 180.000 maravedis, além dos serviços que lhe tinha prestado durante três anos, antes de 1492. "Digo e confieso... que el Señor Almirante Don Cristobal Colón me deve e es obligado a dar e pagar por su cuenta corriente 180 mil nuaravedis, poco mais ó menos, segun por mis libros parecerá, y mas el servicio y trabajo que yo por su Señoria e por sus... negocios

(10). - Monsignor Geraldini, It., lib. XIX, p. 205.

(11). - Cesaréo Fernandez, Duro, Nebulosa de Colón, Madrí, 1890, pp. 174-177. 
he hecho y trabajado tres anos ha" (12). Não só a operação do empréstimo da segunda metade do capital necessário ao negócio foi feito juntamente por Santangel e Pinello, mas a famosa primeira capitulação de Santa Fé é redigida por Juan de Coloma, catalão, secretário do rei e a segunda é também redigida pelo mesmo Coloma, que desta vez comparece como secretário comum dos soberanos. E - rascunho da primeira capitulação foi feito pelo padre Pérez por conta de Colombo e por Coloma por conta do rei. Em suma, todos êstes fatos revelam o perfeito acôrdo entre as duas partes interessadas: Colombo, Pinello, financeiros italianos, Santangel, rei Fernanào, elemento aragonês-cataláo. A participação da rainha Isabel se reduz em aprovar a resolução de seu augusto espôso e a de dar à emprêsa aquêle caráter religioso e cavaleiresco que estava de acôrdo com o temperamento do povo espanhol e que criou para ela uma tão sedutora lenda. Mas o fato que da primeira expedição não fêz parte nenhum religioso, serve para dar uma nova prova que essa foi exclusivamente uma emprêsa comercial realizada ùnicamente pelos genoveses com simples beneplácito do rei de Aragão e sob a aparência patronal da rainha de Castela".

"Uma outra questão resta ser resolvida: se, como é fora de contestação, a metade do capital foi fornecida pelos amigos italianos de Colombo, preponderando os genoveses, como pôde ser constituida a outra nominalmente entregue por Santangel e Pinello? Ou teria a participaçáo dos "escribanos de ración" sida efetiva ou fictícia? Sabemos que Santangel era homem positivo, habituado a realizar regócios seguros; podemos em conseqüência deduzir que êle não desejava empregar os seus capitais em especulações de manifesto risco $\epsilon$ incerteza como aquelas propostas por Colombo, que se baseava tôdas no acaso. Se êle se prestou a favorecer o projeto do Genovês e de seus amigos e associados, não devia ter feito tanto pela miragem de obter um bom lucro sôbre a quota do capital que podia empregar no negócio, mas com um objetivo mais elevado e profundo. Recordemos que os banqueiros e mercadores genoveses eram donos do mercado financeiro da Espanha; que só junto dêles os arruinados tesoureiros dos dois reinos podiam encontrar os fundos líquidos de que tinham contínua necessidade; que já outra vez o rei Férnando, com a interferência de Santangel, tinha obtido dêles abertura de crédito; aumentando-se os grupos capitalistas italianos ao redor de Colombo, o astuto valenciano via-se obrigado pelo seu objetivo fiuturo a assegurar ao rei os financiamentos que êste podia ainda r.ecessitar, reforçava portanto o próprio crédito e o próprio poder de modo a desafiar o ódio e a inveja que a própria origem hebraica e \& própria insolente fortuna provocavam. De outro lado, os Pinello, cs Berardi, os Centurione, os Doria, os Spinola, os Italiano, os Cattaneo, os Di Negro, os Rivaloro, que contribuiram tão largamente para subvencionar o armamento das viagens sucessivas de Colombo, estavam em condições de cobrir tôdas as despêsas da primeira ex-

(12). - Duquesa d'Alba, obra citada, p. 8. 
Đedição. Seria estranho que êles além de pedirem a Santangel o seu valiosissimo apôio junto ao rei Fernando, e além de ter-lhe confiado a missão de comunicar à rainha Isabel o desêjo do espôso (em vez de desêjo não seria melhor falar de vontade?) lhe tivesse tam¿ém solicitado um auxilio de dinheiro. De qualquer modo, na meIhor das hipóteses, Santangel não participou da constituição do capital se não em parte mínima. O fato de que êle não tomou nenhuma parte, nem administrativa, nem de cotêjo dos fundos da em.prêsa é um indicio sintomático. Igualmente se pode deduzir que dada a ingerência que teve Pinello naquela administração e naquele cotêjo, a sua quota de capital devia ser a mais importante de tôdas".

"Em conclusão: se à emprêsa de que resultou o' descobrimento do Novo Mundo pôde ser finalmente realizada, depois que o rei e or poderosos da Côrte, os cosmógrafos, os teólogos, os doutos e os entendidos haviam declarado absurda e extravagante, isso se deve ao fato de que Colombo, fortemente apoiado pelos seus conterrâneós; banqueiros, armadores e mercadores, the deu uma nova diretriz, tirando-lhe a logomaquia doutrinária e levando-a para o terreno prático dos negócios comerciais. A batida aos hebreus, concretizada em .janeiro de 1492, veio num momento singularmente oportuno e foi um bom jôgo para os que apoiavam a emprêsa, os quais encontraram -m Santangel, ligado a êles pela amizade e pelo interêsse, o mediacor junto ao rei. $O$ rei Fernando compreendeu quais as vantagens que podia tirar da situação: se a emprêsa andasse mal, nenhum prejuizo lhe adivinha, porque a suportar as despêsas estavam aquêles €strangeiros, junto dos quais e de qualquer modo praticava um ato que requeria compensação: se andasse bem êle teria obtido as maiores vantagens. A conduta do rei com relação a Colombo, depois que - inverossimil acontecimento se realizou, demonstra a evidência de que negros pensamentos estava possuido quando em abril de 1492 cencedia ao importuno Genovês vantagens e privilégios incríveis. Foi com o dinheiro inteiramente ou em grande parte pôsto à disposição de Cristóforo Colombo pelos seus conterrâneos residentes na Fspanha que a grande emprêsa se tornou possível: a glória de havê-la concebido, formulada, defendida, financiada, preparada, concluída, é pois ùnicamente e totalmente italiana".

O erudito estudo de Rinaldo Caddeo, como acabamos de $v \in r$, sôbre o financiamento da primeira viagem de Colombo ao Novo Mundo evidencia, como já sabíamos, não ter sido êle um cisionário nem um aventureiro qualquer que aparece inexplicàvelmente, primeiro em Portugal e depois na Espanha, em busca de auxílio ao seu projeto que consistia em atingir a Ásia pela rota do Ocidente, emprêsa baseada em princípios científicos certos e não refutados, isto é, na forma esférica da Terra, herança da época clássica, difundida principalmente na Italia do Renascimento. De fato, a idéia de atravessar o Mar Oceano para atingir o Japão e a China, não brotou espontâ- 
neamente no cérebro de Colombo, como acertadamente diz Henry Harrisse. Os historiadores encontram essa concepção no que escreveram Aristóteles, Roger Bacon, Paulo Toscanelli, Jerome Münzmeister's, Martim Behaim e outros sábios da Antigüidade, da Idade Média, da Idade Moderna, notando-se que ela não era um simples conceito do espírito, isolada, mais ou menos vaga, porém apoiada em raciocínio, em deduções científicas, como expunha Colombo. No século XV, o projeto de Colombo tinha saído do domínio da especulação e os sábios procuravam com ardor o meio de realizá-la.

A avidez das especiarias, das drogas, das pedras preciosas e do ouro do Oriente, que levou Portugal a procurar o caminho marítimo para a fndia contornando o continente negro, foi também o móvel que induziu os banqueiros, os mercadores e os armadores genoveses da Espanha a financiarem a grande emprêsa de Colombo. A propagação da fé, foi em realidade. um engôdo. Isso fica evidenciado quando verificamos que desde as primeiras expedições portuguêsas às costas ocidentais da Africa e, depois, em busca da fndia, inclusive aquela de Vasco da Gama, nenhuma delas teve a bordo qualquer padre, qualquer frade, qualquer missionário. $O$ mesmo podemos dizer da emprêsa de Colombo e das primeiras viagens dos espanhóis ao Novo Mundo.

Assim, como D. João II e D. Manuel, de Portugal, recorreram a banqueiros e mercadores italianos, notadamente aos florentinos Bartolomeu Marchioni e Girolomo Sernigi para a realização do Plano da fndia, porque escassos eram os recursos monetários do reino, do mesmo modo, como evidenciou Rinaldo Caddeo, procederam os Reis Católicos, o que vem provar que os dois grandes feitos marítimos da Idade Moderna (o de Vasco da Gama e o de Colombo), muito devem aos italianos da Península Ibérica, fato êste que deve ser pôsto em relêvo quando, sem parti-pris, estudamos os grandes feitos marítimos dos séculos XV e XVI. 